\title{
Living alone and psychological well-being in mid-life: does partnership history matter?
}

\author{
Dieter Demey, ${ }^{1}$ Ann Berrington, ${ }^{1}$ Maria Evandrou, ${ }^{2}$ Jane Falkingham ${ }^{1}$
}

${ }^{1}$ ESRC Centre for Population Change, University of

Southampton, Southampton UK

${ }^{2}$ ESRC Centre for Population Change, Centre for Research on Ageing, Social Sciences, University of Southampton, Southampton, UK

\section{Correspondence to}

Dieter Demey, ESRC Centre for Population Change, School of Social Sciences, University of Southampton, Room 2043, Building 58, Highfield, Southampton S017 1BJ, UK; D.Demey@soton.ac.uk

Received 3 June 2013 Revised 9 October 2013 Accepted 28 November 2013 Published Online First 9 January 2014

\section{ABSTRACT}

Background Previous studies have found that the duration since a union dissolution and the number of union dissolutions are associated with psychological well-being. However, these two aspects of partnership history have rarely been considered jointly in models of mental health. This study aims to investigate how the time since the most recent union dissolution and the number of union dissolutions are related to two indicators of psychological well-being — life satisfaction and the General Health Questionnaire-among middle-aged solo-living British men and women.

Methods Data from the United Kingdom Household Longitudinal Study from 2009 to 2010 are analysed for 1201 50-64 year olds who were living alone and have ever been in a co-resident union (472 men and 729 women). Logistic regression analysis is used to investigate how life satisfaction and General Health Questionnaire 12 (GHQ-12) caseness are associated with partnership characteristics.

Results GHQ-12 caseness is significantly and positively associated with the number of union dissolutions and negatively with the duration since the most recent union dissolution. This is the case among both genders, in models in which these partnership characteristics are entered separately and jointly, and in models controlling for parenthood status, socioeconomic status and physical health.

Conclusions The results suggest that there is a shortterm deterioration in mental health after a partnership break-up and that experiencing multiple union dissolutions is detrimental for psychological well-being. The association between partnership characteristics and the two measures of psychological well-being differs, which is in line with previous research showing that negative affect and life satisfaction are two separate constructs.

\section{INTRODUCTION}

The number of people in mid-life who have experienced a partnership dissolution is increasing as a result of the historical rises in separation and divorce rates and the ageing of the large postwar birth cohorts of the late 1940s and early 1960s. Previous research has found that individuals who are separated, divorced and widowed tend to have lower levels of psychological well-being than those who are married or cohabiting. ${ }^{1-6}$ Many of the divorced who do not re-partner are likely to live alone in mid-life, particularly after their dependent children leave home. ${ }^{7}$ Recent research has highlighted that living alone is increasingly common in this life-course phase ${ }^{8}$ and is itself related to poor physical health. ${ }^{910}$ Those with poor mental health are more likely to also be in poor physical health and have higher mortality rates. ${ }^{11}{ }^{12}$ From a policy perspective, the rise in living alone in mid-life is of concern since those who are living alone in later life are less likely to receive support from informal sources ${ }^{13}$ and display a higher use of formal services $^{14}$ than those who are not living alone.

Although previous studies have found that a union dissolution has both short-term and longterm implications for psychological well-being, most have focused on changes in psychological well-being in the period around a partnership break-up. Most of these studies have used prospective data with repeated measures on psychological well-being and have shown that the deterioration in psychological well-being surrounding the time of a union dissolution is of relatively short duration. ${ }^{1} \quad 4-6 \quad 15$ However, there is also empirical evidence indicating that those who have experienced multiple partnership transitions have lower psychological well-being. ${ }^{6}{ }^{16}$ Nevertheless, previous studies on psychological well-being have rarely jointly considered the duration since the most recent union dissolution and the number of union transitions. One study has shown that loneliness among older Dutch unpartnered adults is related to both the duration since the most recent union dissolution and the number of union dissolutions. ${ }^{6}$ This raises the question whether their findings are applicable to younger age groups and different contexts, and whether they are robust for different psychological well-being indicators.

Psychological well-being is a multidimensional concept consisting of both negative aspects (eg, loneliness or depression) and positive aspects (eg, happiness or self-esteem). ${ }^{2}$ The relationship between psychological well-being and marital status depends on the particular aspect of psychological well-being that is investigated. ${ }^{2}$ For instance, although the separated and divorced report more psychological distress than those who are married, they also report a higher degree of autonomy and personal growth. ${ }^{2}$ Another study has found differences in life satisfaction between 'divorced and single' and 'married and never divorced' older Australian men, though not with respect to the Short Form Health Survey. ${ }^{17}$ Other studies that have investigated the relationship between partnership characteristics and more than one indicator of psychological well-being have found similar associations with alternative indicators of psychological well-being. A study on middle-aged Dutch men has found lower levels of both life satisfaction and mental health among the formerly partnered compared with those who are married. ${ }^{18}$ Other work has found that the decline and recovery in General Health Questionnaire (GHQ) and life satisfaction scores in the time around a marital dissolution were analogous. ${ }^{1}$ 
This paper uses data from the United Kingdom Household Longitudinal Study (UKHLS) to investigate how the time since the most recent union dissolution and the number of union dissolutions are related to two indicators of current psychological well-being-life satisfaction and GHQ-12-among 5064-year-old solo-living British men and women. The study contributes to the literature on well-being by (i) taking into account both the number of union dissolutions and the duration since the most recent union dissolution, (ii) considering more than one indicator of psychological well-being and (iii) focusing on people who are living alone in mid-life-a neglected phase of the life course.

Two research questions are addressed:

1. How are the number of union dissolutions and the time since the most recent union dissolution related to psychological well-being among those living alone in late mid-life (50-64 years of age)?

2. Does this relationship depend on the particular indicator of psychological well-being?

There is an ongoing debate in the literature on whether differences in psychological well-being according to marital status result from the selection into singlehood by socioeconomic status, the selection of those in poor mental health into union dissolution, the protective effects of a partnership or of the effect of a union dissolution on mental health. The chances of entering a co-resident union differ by socioeconomic status (social selection); those in poor mental health display a higher probability of union dissolution (selection into union dissolution), and having a partner could have positive health effects (protective effect). Also, the experience of losing a partner can heighten psychological distress (causation effect). This study relates retrospectively collected data on past unions to psychological well-being measured at the time of the survey. It is not possible to examine whether the association between partnership histories and psychological well-being is due to a selection of those in poor mental health into union dissolution since no data were collected on respondents' mental health in past unions. However, it is possible to assess the extent to which the association between partnership characteristics and psychological well-being is explained by social selection. A third research question addressed here is therefore

1. How is the relationship between partnership history and psychological well-being mediated by socioeconomic status?

\section{METHODS}

\section{Study population}

The UKHLS collects data on a sample of households representative of the UK population. Interviews for the first round of data collection, used here, were carried out in 2009 and 2010. In total, 30169 households provided a productive interview and 50994 adults completed the individual questionnaire. ${ }^{19}$ The first-wave household response rate among eligible households is $58 \%$ in the general population (GP) sample and 52\% in the ethnic minority boost (EMB) sample. The first-wave individual full-interview response rate among participating households is $82 \%$ in the GP sample and $72 \%$ in the EMB sample. For an analysis of non-response in the first wave, see ref. 20 All adults (aged 16 years and over) were presented with an individual questionnaire and a self-completion questionnaire. The selfcompletion questionnaire is present for $85 \%$ of those with a non-proxy individual interview. A comparison of the demographic and socioeconomic characteristics of those who did and did not complete the self-completion questionnaire indicates that there are no differences in the characteristics of these two groups (analysis available upon request). The data are weighted with the individual-level full and self-completion interview weight (see ref. 19).

Men and women aged 50-64 years who were living alone at the time of the survey and provided non-missing information are selected. The total unweighted sample size is 1457 (630 men, 827 women): 256 of whom have never been in a co-resident union (158 men, 98 women) and 1201 (472 men, 729 women) who have ever been in a co-resident union.

\section{Outcome measures}

Two indicators of psychological well-being, life satisfaction and GHQ caseness, are used. Adults were asked to indicate their satisfaction with life on a seven-point scale ranging from completely dissatisfied to completely satisfied. The second indicator is based on the GHQ, which contains 12 questions, each with a four-point scale, on several aspects related to psychological distress such as concentration, sleep, perception of usefulness, decision making, strain, enjoyment of day-to-day activities, ability to face problems, unhappiness, confidence and self-worth. By recoding the values 1 and 2 ('same as or better than usual') to 0 , and values 3 and 4 to 1 ('less or much less than usual') and summing these values, a score is calculated ranging from 0 (the least distressed) to 12 (the most distressed). Scores of 3 or higher are considered to indicate poor psychological well-being in the UK context, ${ }^{21}$ and a threshold of 4 has been adopted in previous research on the UK. ${ }^{4}$ The score is therefore dichotomised, namely, values of $0-3$ into ' 0 ' $=$ no case and $4-12$ into ' 1 '= case.

One of the aims of this study is to investigate whether the association between the partnership variables and psychological well-being depends on the indicator of psychological well-being used, and this assessment is facilitated by dichotomising life satisfaction. However, in contrast to the GHQ, there is no clear guidance in the literature on the appropriate cut-off point for life satisfaction. Sensitivity analyses were undertaken in preliminary analyses (available upon request) first with three different cut-off points ('somewhat dissatisfied', 'mostly dissatisfied' and 'completely dissatisfied') and then running the model using ordinal logistic regression. Results for the partnership variables in all models are almost identical. Here, life satisfaction is dichotomised into ' 0 ' $=$ not dissatisfied ('neither satisfied or dissatisfied', 'somewhat satisfied', 'mostly satisfied', 'completely satisfied') and ' 1 '=dissatisfied ('somewhat dissatisfied', 'mostly dissatisfied', 'completely dissatisfied').

\section{Union history}

Retrospective data on partnership trajectories are used to construct the following variables of union history: ever in a co-resident union (no, yes); the number of union dissolutions (one, more than one); the duration since the most recent union dissolution (less than 1 year, 1-2 years, 2-4 years, 4-9 years, 10 + years). A union can be a marriage, civil partnership or a freestanding cohabitation of at least 3 months. It is possible that psychological well-being differs between those who have been in a cohabiting or a marital union. However, only $13 \%$ of men and $5 \%$ of women who are living alone and are aged 55-64 years have ever cohabited but have never married, ${ }^{22}$ and for this reason cohabiting and marital unions are combined. The date of the most recent dissolution of a cohabiting union refers to the year and month the cohabitation ceased, and of a marital or civil partnership union to the year and month of the separation, divorce (if there is no date of separation), or the death of a partner. 


\section{Control variables}

Several control variables are included in the model following previous research on well-being. Psychological well-being changes by age. ${ }^{15} 61518$ Parenthood status has been both negatively and positively associated with psychological wellbeing. ${ }^{2} 23$ Educational level has also been found to be associated with psychological well-being. ${ }^{1}{ }^{18}$ Housing tenure, income and current economic activity are important indicators of socioeconomic status in the UK. Preliminary analyses showed poorer psychological well-being for those who are not employed. This is probably because a substantial number in this group are in poor physical health (which is related to mental health). Current economic activity is therefore not included in the analysis. However, an indicator for physical health has been included. The control variables are categorised as follows:

age (50-54 years, 55-59 years, 60-64 years);

non-resident children (no, yes);

educational level (higher education, some qualifications, no qualifications);

housing tenure (owner-occupier, rented, social housing);

total monthly personal income (quintiles);

(self-reported physical) health limits daily activities (no, yes).

Previous research has identified that the impact of a partner's death on psychological well-being is stronger than that of losing a partner through union dissolution. ${ }^{1}{ }^{4}$ Unfortunately, UKHLS did not include a question on the reason for the cessation of cohabiting unions, even though a non-negligible proportion of those living alone in mid-life have ever been in a cohabiting union but have never been married. ${ }^{22}$ A control for the type of union dissolution is therefore not included in the analysis. Preliminary analysis showed that marital status-distinguishing between the never married, separated/divorced and widowedis not significant, and that including marital status in the model does not alter the association between partnership characteristics and psychological well-being.

\section{Analysis}

Dissatisfaction with life and GHQ-12 caseness are modelled using logistic regression analysis. Model 1 investigates differences in psychological well-being between solo-living men and women who have never and ever been in a co-resident union. The remainder of the analysis focuses on the latter group and adopts a stepwise modelling approach. In the first two steps, the associations between psychological well-being and the number of union dissolutions (model 2) and the duration since the most recent union dissolution (model 3) are considered separately. In model 4, the two partnership variables are included in the model. Models 5 and 6 add the control variables. Previous research has found that the impact of a union dissolution on health could be stronger for women than for men, ${ }^{15} 25$ and that men and women follow different union and parenthood pathways into living alone. ${ }^{22}$ All models are therefore estimated separately for men and women. Tests for interactions between gender and the partnership variables have been conducted on a pooled dataset including both men and women. The results of this analysis are discussed in the text if a significant difference was found. Insignificant control variables are retained in the models because they are of substantive interest.

\section{RESULTS}

\section{Descriptive results}

Table 1 shows the proportion of men and women aged 5064 years who report being dissatisfied with life and who are a GHQ-12 case by living arrangement (living alone or not). Almost a quarter of solo-living men and women are dissatisfied with life compared with less than $15 \%$ for those who are not living alone. Almost a quarter of solo-living men are a GHQ-12 case compared with less than $15 \%$ for men who are not living alone. Thirty per cent of women living alone are a GHQ-12 case compared with nineteen per cent of women not living alone.

\section{Multivariate results}

The results for the logistic regression analysis of dissatisfaction with life and GHQ-12 caseness among those mid-lifers living alone are shown in tables 2 (men) and 3 (women). The analytical sample for model 1 includes all aged 50-64 years who are living alone, while models 2-6 include only those who are living alone and have ever been in a co-resident union. Model 1 shows that the odds of dissatisfaction with life and GHQ-12 caseness decrease with age. Model 2 shows that the number of union dissolutions is positively associated to dissatisfaction with life among women $(\mathrm{p}<0.01)$, and to GHQ-12 caseness among men $(\mathrm{p}<0.01)$ and women $(\mathrm{p}<0.05)$. Model 3 shows that-compared with those whose union dissolved less than 1 year agoodds of GHQ-12 caseness are lower for men 4-9 years $(p<0.05)$ after the union dissolution, and for women $2-4(\mathrm{p}<0.05), 4-9$ $(\mathrm{p}<0.01)$ and $10+$ years $(\mathrm{p}<0.01)$ after the union dissolution. Practically none of the coefficients in models 3-6 for the duration since the most recent union dissolution are significantly

Table 1 Dissatisfaction with life and GHQ-12 caseness among mid-life men and women (aged 50-64) by whether living alone or not (\%)

\begin{tabular}{|c|c|c|c|c|c|c|c|c|c|c|}
\hline & \multicolumn{4}{|c|}{ Dissatisfied } & \multicolumn{4}{|c|}{ GHQ-12 case } & \multicolumn{2}{|l|}{ Total } \\
\hline & \multicolumn{2}{|l|}{ No } & \multicolumn{2}{|l|}{ Yes } & \multicolumn{2}{|l|}{ No } & \multicolumn{2}{|l|}{ Yes } & \multirow[b]{2}{*}{$n$} & \multirow[b]{2}{*}{$\%$} \\
\hline & $\mathbf{n}$ & $\%$ & $\mathrm{n}$ & $\%$ & $\mathrm{n}$ & $\%$ & $\mathbf{n}$ & $\%$ & & \\
\hline \multicolumn{11}{|l|}{ Men } \\
\hline Not living alone & 3084 & 86 & 510 & 14 & 3075 & 86 & 519 & 14 & 3594 & 100 \\
\hline Living alone & 440 & 76 & 140 & 24 & 443 & 76 & 138 & 24 & 580 & 100 \\
\hline Total & 3524 & 84 & 650 & 16 & 3518 & 84 & 656 & 16 & 4174 & 100 \\
\hline \multicolumn{11}{|l|}{ Women } \\
\hline Not living alone & 3147 & 86 & 496 & 14 & 2936 & 81 & 708 & 19 & 3644 & 100 \\
\hline Living alone & 513 & 77 & 154 & 23 & 469 & 70 & 197 & 30 & 667 & 100 \\
\hline Total & 3660 & 85 & 650 & 15 & 3405 & 79 & 905 & 21 & 4310 & 100 \\
\hline
\end{tabular}

Weighted counts and proportions, numbers may not add up due to rounding.

GHQ-12, General Health Questionnaire 12. 
Table 2 Logistic regression of dissatisfaction with life and GHQ-12 caseness, men living alone

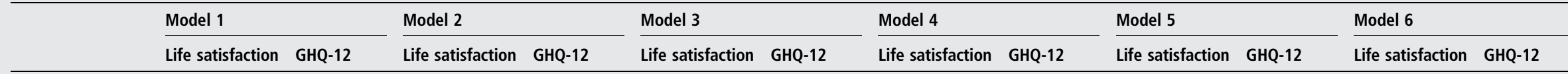

Age

\begin{tabular}{|c|c|c|c|c|c|c|c|c|c|c|c|c|}
\hline 50-54 (ref. cat.) & 1.00 & 1.00 & 1.00 & 1.00 & 1.00 & 1.00 & 1.00 & 1.00 & 1.00 & 1.00 & 1.00 & 1.00 \\
\hline $55-59$ & 0.90 & $0.57^{*}$ & 0.93 & 0.80 & 0.92 & 0.73 & 0.93 & 0.79 & 0.87 & 0.63 & 0.87 & 0.65 \\
\hline & (0.56 to 1.46 ) & (0.34 to 0.96 ) & (0.52 to 1.64 ) & (0.43 to 1.52 ) & (0.52 to 1.60$)$ & (0.39 to 1.38 ) & (0.53 to 1.63 ) & (0.42 to 1.48 ) & (0.48 to 1.56$)$ & (0.33 to 1.23 ) & (0.47 to 1.60$)$ & (0.34 to 1.26 ) \\
\hline-64 & $0.56^{*}$ & $0.54^{*}$ & 0.58 & 0.85 & 0.58 & 0.76 & 0.59 & 0.85 & $0.47^{*}$ & 0.74 & $0.40^{* *}$ & 0.62 \\
\hline
\end{tabular}

Ever in a co-resident union

$\begin{array}{lll}\text { No (ref. cat.) } & 1.00 & 1.00 \\ \text { Yes } & 1.14 & 0.82 \\ & (0.72 \text { to } 1.81) & (0.52 \text { to } 1.29)\end{array}$

Number of union dissolutions

One (ref. cat.)

More than one

$\begin{array}{ll}1.00 & 1.00 \\ 1.18 & 2.24^{* *} \\ \text { (0.73 to 1.91) } & \text { (1.37 to } 3.65)\end{array}$

Duration since most recent union dissolution

Less than 1 year

(ref. cat.)

1-2 years

$2-4$ years

4-9 years

$10+$ years

Non-resident children

No (ref. cat.)

Yes

Educational level

Higher education

(ref. cat.)

Some qualifications

No qualifications

1.00

0.41

(0.12 to 1.38$)$

1.21

(0.43 to 3.47 )

0.75

(0.31 to 1.81 )

0.71

(0.30 to 1.66$)$
1.00

1.16

(0.72 to 1.87$)$

1.00

0.45

0.94

1.22

(0.15 to 0.99$) \quad(0.30$ to 1.79 )

0.66

0.73

(0.28 to 1.56$) \quad(0.31$ to 1.72$)$
1.00

$2.58^{* *}$

(1.57 to 4.24$) \quad(0.69$ to 1.85$)$

1.00

0.44

0.95

(0.32 to 2.78$) \quad(0.32$ to 2.61$)$

0.35

$(0.13$ to 0.90$) \quad(0.23$ to 1.38$)$

0.79

0.47

(0.33 to 1.91$) \quad$ (0.19 to 1.14$)$ $\begin{array}{lll}1.00 & 1.00 & 1.00\end{array}$

$2.78^{* *} \quad 1.11 \quad 2.98^{* *}$

(1.63 to 4.71$) \quad$ (0.66 to 1.86$) \quad$ (1.69 to 5.26$)$

$\begin{array}{lll}1.00 & 1.00 & 1.00\end{array}$

$0.28 \quad 0.23$ *

(0.07 to 1.20$) \quad$ (0.06 to 0.84$)$

$0.65 \quad 0.86$

(0.23 to 1.78 ) (0.30 to 2.46$)$

$0.23^{* *} \quad 0.45$

(0.09 to 0.61$) \quad$ (0.18 to 1.11$)$

$0.37^{*} \quad 0.37^{*}$

(0.14 to 0.96$) \quad(0.15$ to 0.91$)$

1.00

1.60

(0.91 to 2.79)

1.00

0.90

1.00

1.44

(0.51 to 1.57$) \quad(0.80$ to 2.56$)$

1.00

1.33

(0.68 to 2.60)

1.00

1.00

1.24

(0.52 to 2.28$) \quad(0.63$ to 2.44$)$

1.04

(0.49 to 2.19)

0.75

0.95

(0.32 to 1.76 ) (0.45 to 1.99 )

1.00

1.00

1.00

0.59

(0.29 to 1.21$)$
$0.76 \quad 0.57$

(0.35 to 1.67$) \quad(0.27$ to 1.22$)$

Rented

(0.31 to 1.63)




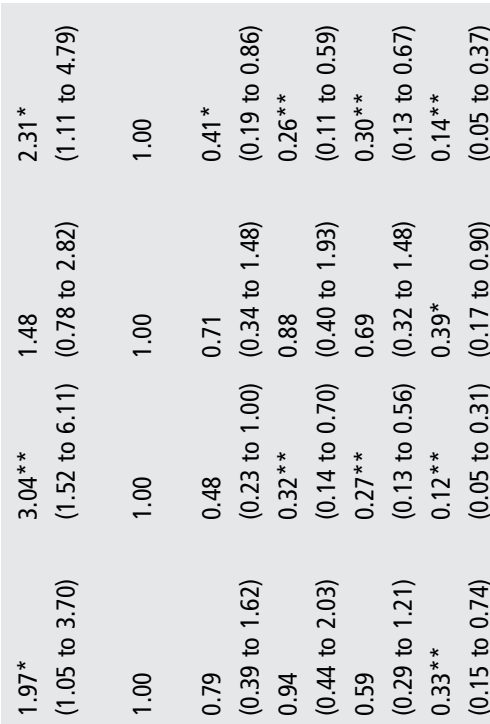

associated with life satisfaction. When the number of union dissolutions and the duration since the most recent union dissolution are both entered in model 4 , the ORs and $p$ values are not fundamentally altered compared with when these partnership variables are considered separately in models 2 and 3 .

Tests for an interaction between gender and the partnership variables on the pooled dataset for men and women (results available upon request) show that women have significantly higher odds of GHQ-12 caseness in the first year after the union dissolution compared with men in the first year after the union dissolution $(p<0.05)$. This association is weaker and insignificant $(p>0.05)$ in the models that contain the control variables (models 5 and 6).

Adding controls for parenthood and socioeconomic status in model 5 strengthens the associations of the number of union dissolutions and the duration since the most recent union dissolution with GHQ-12 caseness for men. Further analysis (not shown) shows that this is mainly related to the inclusion of housing tenure and income in the model. Parenthood status is not associated with psychological well-being, having no qualifications lowers psychological well-being among women $(p<0.05)$, renting is positively associated with dissatisfaction with life among women $(\mathrm{p}<0.01)$, social housing is positively associated with GHQ-12 caseness among women and men $(\mathrm{p}<0.01)$ and income is strongly and negatively associated with GHQ-12 caseness.

Including physical health in model 6 strengthens the association of the duration since the most recent union dissolution with dissatisfaction with life, and the association of the number of union dissolutions and the duration since the most recent union dissolution with GHQ-12 caseness for men. When compared with model 5, there is no significant association between social housing and dissatisfaction with life among men and between social housing and GHQ-12 caseness among women. There is a strong and significant $(\mathrm{p}<0.01)$ association between physical health and psychological well-being.

\section{DISCUSSION}

This study has investigated how psychological well-being among those living alone in mid-life is associated with the number of union dissolutions and the duration since the most recent union dissolution. In line with previous research, it has found that each of these two partnership characteristics has a strong and significant effect on GHQ-12 caseness. ${ }^{1}{ }^{4-6} 1516$ This is also true when both the number of union dissolutions and the duration since the most recent union dissolution are taken into consideration. This confirms the results of a previous study where a similar model was estimated but that focused on a different study population and used a different psychological well-being indicator. ${ }^{6}$ The results suggest that the experience of a union dissolution has a detrimental short-term impact on psychological well-being and that there is a cumulative effect of experiencing multiple union dissolutions on psychological well-being in the longer term. This would advocate to investigate the effect of union dissolution on psychological well-being in the long run, as has also been argued in the literature on physical health. ${ }^{25}$ Another key finding is that, in the first year after a union dissolution, women's mental health is poorer than men's. This has also been reported in previous research looking at the associations between union dissolution and physical health. ${ }^{25}$ One possible explanation is that the economic impact of losing a partner is stronger for women than for men. This hypothesis finds support in the fact that this gender difference disappears when controlling for socioeconomic characteristics. 
Table 3 Logistic regression of dissatisfaction with life and GHQ-12 caseness, women living alone

\begin{tabular}{|c|c|c|c|c|c|c|c|c|c|c|c|c|}
\hline & \multicolumn{2}{|l|}{ Model 1} & \multicolumn{2}{|l|}{ Model 2} & \multicolumn{2}{|l|}{ Model 3} & \multicolumn{2}{|l|}{ Model 4} & \multicolumn{2}{|l|}{ Model 5} & \multicolumn{2}{|l|}{ Model 6} \\
\hline & Life satisfaction & GHQ-12 & Life satisfaction & GHQ-12 & Life satisfaction & GHQ-12 & Life satisfaction & GHQ-12 & Life satisfaction & GHQ-12 & Life satisfaction & GHQ-12 \\
\hline \multicolumn{13}{|l|}{ Age } \\
\hline 50-54 (ref. cat.) & 1.00 & 1.00 & 1.00 & 1.00 & 1.00 & 1.00 & 1.00 & 1.00 & 1.00 & 1.00 & 1.00 & 1.00 \\
\hline $55-59$ & $\begin{array}{l}0.67 \\
\text { (0.44 to } 1.02 \text { ) }\end{array}$ & $\begin{array}{l}0.74 \\
\text { (0.50 to } 1.11 \text { ) }\end{array}$ & $\begin{array}{l}0.66 \\
(0.42 \text { to } 1.02)\end{array}$ & $\begin{array}{l}0.79 \\
\text { (0.51 to } 1.21 \text { ) }\end{array}$ & $\begin{array}{l}0.68 \\
\text { (0.43 to } 1.06 \text { ) }\end{array}$ & $\begin{array}{l}0.82 \\
(0.53 \text { to } 1.26)\end{array}$ & $\begin{array}{l}0.66 \\
\text { (0.42 to } 1.03 \text { ) }\end{array}$ & $\begin{array}{l}0.80 \\
(0.52 \text { to } 1.24)\end{array}$ & $\begin{array}{l}0.70 \\
\text { (0.44 to } 1.11 \text { ) }\end{array}$ & $\begin{array}{l}0.80 \\
\text { (0.50 to } 1.26 \text { ) }\end{array}$ & $\begin{array}{l}0.62 \\
\text { (0.38 to } 1.00 \text { ) }\end{array}$ & $\begin{array}{l}0.69 \\
(0.43 \text { to } 1.12)\end{array}$ \\
\hline $60-64$ & $\begin{array}{l}0.43^{* *} \\
(0.28 \text { to } 0.66)\end{array}$ & $\begin{array}{l}0.56^{* *} \\
(0.38 \text { to } 0.83)\end{array}$ & $\begin{array}{l}0.42^{* *} \\
(0.27 \text { to } 0.65)\end{array}$ & $\begin{array}{l}0.56^{* *} \\
\text { (0.37 to } 0.84)\end{array}$ & $\begin{array}{l}0.43^{* *} \\
(0.28 \text { to } 0.68)\end{array}$ & $\begin{array}{l}0.59^{*} \\
(0.38 \text { to } 0.90)\end{array}$ & $\begin{array}{l}0.43^{* *} \\
(0.27 \text { to } 0.68)\end{array}$ & $\begin{array}{l}0.58^{*} \\
(0.38 \text { to } 0.89)\end{array}$ & $\begin{array}{l}0.45^{* *} \\
(0.28 \text { to } 0.74)\end{array}$ & $\begin{array}{l}0.56^{*} \\
(0.36 \text { to } 0.88)\end{array}$ & $\begin{array}{l}0.40^{* *} \\
(0.24 \text { to } 0.67)\end{array}$ & $\begin{array}{l}0.49^{* *} \\
(0.31 \text { to } 0.80)\end{array}$ \\
\hline \multicolumn{13}{|l|}{ Ever in a co-resident union } \\
\hline No (ref. cat.) & 1.00 & 1.00 & & & & & & & & & & \\
\hline Yes & $\begin{array}{l}1.53 \\
\text { (0.86 to } 2.73 \text { ) }\end{array}$ & $\begin{array}{l}1.72 \\
\text { (1.00 to } 2.97)\end{array}$ & & & & & & & & & & \\
\hline \multicolumn{13}{|l|}{ Number of union dissolutions } \\
\hline One (ref. cat.) & & & 1.00 & 1.00 & & & 1.00 & 1.00 & 1.00 & 1.00 & 1.00 & 1.00 \\
\hline More than one & & & $\begin{array}{l}1.83^{* *} \\
\text { (1.28 to } 2.63)\end{array}$ & $\begin{array}{l}1.53^{*} \\
\text { (1.09 to } 2.14)\end{array}$ & & & $\begin{array}{l}1.76^{* *} \\
(1.22 \text { to } 2.55)\end{array}$ & $\begin{array}{l}1.51^{*} \\
\text { (1.06 to } 2.15)\end{array}$ & $\begin{array}{l}1.74^{* *} \\
(1.20 \text { to } 2.54)\end{array}$ & $\begin{array}{l}1.57^{*} \\
\text { (1.08 to } 2.27)\end{array}$ & $\begin{array}{l}1.73^{* *} \\
(1.17 \text { to } 2.56)\end{array}$ & $\begin{array}{l}1.55^{*} \\
\text { (1.05 to } 2.28)\end{array}$ \\
\hline \multicolumn{13}{|c|}{ Duration since most recent union dissolution } \\
\hline Less than 1 year (ref. cat.) & & & & & 1.00 & 1.00 & 1.00 & 1.00 & 1.00 & 1.00 & 1.00 & 1.00 \\
\hline $1-2$ years & & & & & $\begin{array}{l}1.03 \\
\text { (0.36 to } 2.91 \text { ) }\end{array}$ & $\begin{array}{l}0.62 \\
(0.23 \text { to } 1.66)\end{array}$ & $\begin{array}{l}1.04 \\
\text { (0.37 to } 2.93 \text { ) }\end{array}$ & $\begin{array}{l}0.62 \\
(0.22 \text { to } 1.70)\end{array}$ & $\begin{array}{l}1.05 \\
\text { (0.37 to } 2.98)\end{array}$ & $\begin{array}{l}0.71 \\
(0.26 \text { to } 1.93)\end{array}$ & $\begin{array}{l}0.97 \\
\text { (0.32 to } 2.89 \text { ) }\end{array}$ & $\begin{array}{l}0.63 \\
(0.21 \text { to } 1.85)\end{array}$ \\
\hline $2-4$ years & & & & & $\begin{array}{l}1.05 \\
\text { (0.42 to } 2.60)\end{array}$ & $\begin{array}{l}0.37^{*} \\
(0.16 \text { to } 0.89)\end{array}$ & $\begin{array}{l}1.03 \\
\text { (0.41 to } 2.57 \text { ) }\end{array}$ & $\begin{array}{l}0.36^{*} \\
(0.15 \text { to } 0.89)\end{array}$ & $\begin{array}{l}1.22 \\
\text { (0.48 to } 3.09 \text { ) }\end{array}$ & $\begin{array}{l}0.42 \\
(0.17 \text { to } 1.04)\end{array}$ & $\begin{array}{l}1.25 \\
\text { (0.45 to } 3.50)\end{array}$ & $\begin{array}{l}0.41 \\
(0.16 \text { to } 1.10)\end{array}$ \\
\hline $4-9$ years & & & & & $\begin{array}{l}0.88 \\
\text { (0.38 to } 2.02 \text { ) }\end{array}$ & $\begin{array}{l}0.28^{* *} \\
(0.12 \text { to } 0.62)\end{array}$ & $\begin{array}{l}0.87 \\
\text { (0.38 to } 2.01 \text { ) }\end{array}$ & $\begin{array}{l}0.27^{* *} \\
(0.12 \text { to } 0.63)\end{array}$ & $\begin{array}{l}0.97 \\
\text { (0.41 to } 2.27 \text { ) }\end{array}$ & $\begin{array}{l}0.28^{* *} \\
(0.12 \text { to } 0.64)\end{array}$ & $\begin{array}{l}0.95 \\
\text { (0.38 to } 2.41 \text { ) }\end{array}$ & $\begin{array}{l}0.25^{* *} \\
(0.10 \text { to } 0.63)\end{array}$ \\
\hline $10+$ years & & & & & $\begin{array}{l}0.70 \\
\text { (0.31 to } 1.55 \text { ) }\end{array}$ & $\begin{array}{l}0.30^{* *} \\
(0.14 \text { to } 0.65)\end{array}$ & $\begin{array}{l}0.78 \\
(0.35 \text { to } 1.73)\end{array}$ & $\begin{array}{l}0.32^{* *} \\
(0.15 \text { to } 0.71)\end{array}$ & $\begin{array}{l}0.87 \\
(0.38 \text { to } 1.95)\end{array}$ & $\begin{array}{l}0.31^{* *} \\
(0.14 \text { to } 0.68)\end{array}$ & $\begin{array}{l}0.85 \\
\text { (0.35 to } 2.07 \text { ) }\end{array}$ & $\begin{array}{l}0.28^{* *} \\
(0.12 \text { to } 0.67)\end{array}$ \\
\hline \multicolumn{13}{|l|}{ Non-resident children } \\
\hline No (ref. cat.) & & & & & & & & & 1.00 & 1.00 & 1.00 & 1.00 \\
\hline Yes & & & & & & & & & $\begin{array}{l}0.82 \\
(0.50 \text { to } 1.34)\end{array}$ & $\begin{array}{l}0.77 \\
(0.49 \text { to } 1.23)\end{array}$ & $\begin{array}{l}0.85 \\
\text { (0.51 to } 1.41 \text { ) }\end{array}$ & $\begin{array}{l}0.81 \\
(0.50 \text { to } 1.30)\end{array}$ \\
\hline \multicolumn{13}{|l|}{ Educational level } \\
\hline Higher education (ref. cat.) & & & & & & & & & 1.00 & 1.00 & 1.00 & 1.00 \\
\hline Some qualifications & & & & & & & & & $\begin{array}{l}1.68 \\
\text { (0.84 to } 3.23 \text { ) }\end{array}$ & $\begin{array}{l}1.43 \\
\text { (0.78 to } 2.62)\end{array}$ & $\begin{array}{l}1.78 \\
\text { (0.92 to } 3.44 \text { ) }\end{array}$ & $\begin{array}{l}1.57 \\
\text { (0.85 to } 2.90)\end{array}$ \\
\hline No qualifications & & & & & & & & & $\begin{array}{l}1.94 \\
\text { (0.95 to } 3.98)\end{array}$ & $\begin{array}{l}1.92 \\
\text { (0.98 to } 3.78)\end{array}$ & $\begin{array}{l}1.95 \\
\text { (0.96 to } 3.67 \text { ) }\end{array}$ & $\begin{array}{l}1.99^{*} \\
(1.00 \text { to } 3.93)\end{array}$ \\
\hline \multicolumn{13}{|l|}{ Housing tenure } \\
\hline Owner-occupier (ref. cat.) & & & & & & & & & 1.00 & 1.00 & 1.00 & 1.00 \\
\hline Rented & & & & & & & & & $\begin{array}{l}2.64^{* *} \\
\text { (1.48 to } 4.69)\end{array}$ & $\begin{array}{l}1.33 \\
\text { (0.76 to } 2.33 \text { ) }\end{array}$ & $\begin{array}{l}2.23^{*} \\
\text { (1.22 to } 4.11)\end{array}$ & $\begin{array}{l}1.08 \\
(0.59 \text { to } 1.95)\end{array}$ \\
\hline Social housing & & & & & & & & & $\begin{array}{l}1.28 \\
(0.82 \text { to } 2.01)\end{array}$ & $\begin{array}{l}1.83^{* *} \\
(1.20 \text { to } 2.78)\end{array}$ & $\begin{array}{l}0.93 \\
(0.57 \text { to } 1.52)\end{array}$ & $\begin{array}{l}1.31 \\
\text { (0.84 to } 2.04 \text { ) }\end{array}$ \\
\hline
\end{tabular}




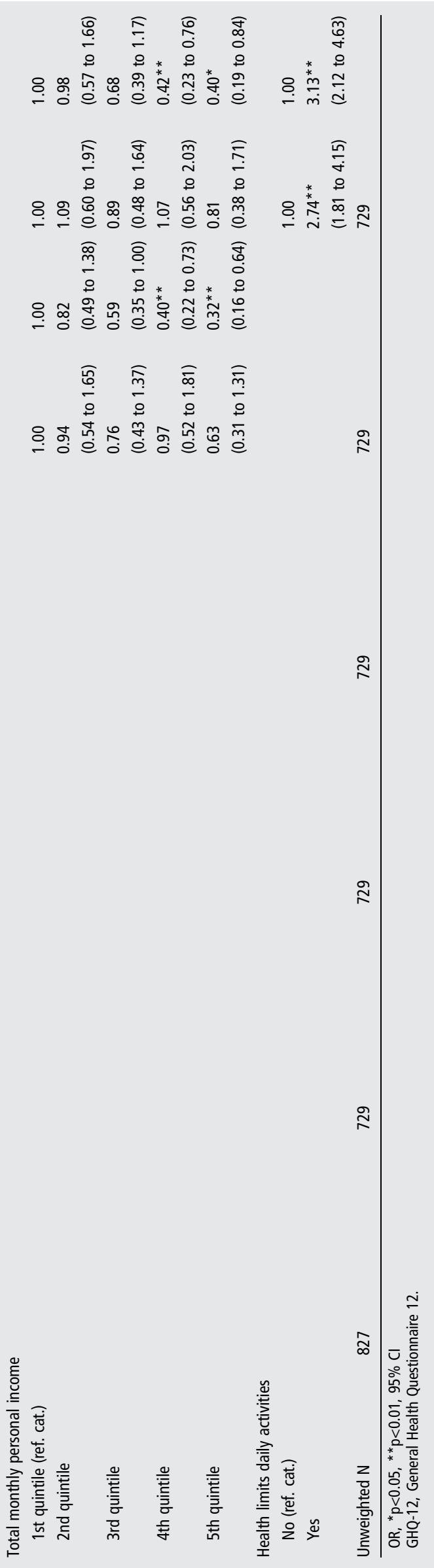

A second finding is that partnership history is more strongly related with GHQ-12 caseness than with life satisfaction. It was found that the number of union dissolutions is associated with poorer life satisfaction in the models for women but not for men. As mentioned in the 'Methods' section, it was checked to see whether this difference in the results between the two outcomes relates to the way in which life satisfaction has been dichotomised, but it was found that the results are robust for different categorisations of life satisfaction. Only in models 4-6 for women is the number of union dissolutions not significant when using 'mostly dissatisfied' as a cut-off point $(0.05<\mathrm{p}<0.10)$, although it is significant again when using 'completely dissatisfied' as a cut-off point $(0.01<\mathrm{p}<0.05)$. It should be noted that the results of previous studies that have looked at more than one indicator of psychological well-being are ambiguous. One possible explanation is that the two indicators of psychological well-being used here measure different aspects of well-being. Those who are in psychological distress according to the GHQ-12 may nevertheless feel a higher degree of autonomy and personal growth because they are living alone, and these could be important aspects of life satisfaction. This would be in line with previous research on psychological wellbeing, which has found that (negative) affect and life satisfaction are two separate constructs. ${ }^{26}$ Also, since the GHQ refers to the usual state of an emotion, it could be more sensitive to recent life events, such as a union dissolution, than life satisfaction. This could explain the absence of an association between the duration since the most recent union dissolution and life satisfaction in most models. However, it is equally possible that levels of psychological distress as measured by the GHQ return to levels observed before the life event, while life satisfaction does not. It has been shown that different components of wellbeing change in different ways over the life course and that change in one domain does not always correspond with change in another. ${ }^{27}$

A third finding is that the association between partnership characteristics and GHQ-12 caseness holds when controlling for parenthood status, socioeconomic characteristics and physical health. Thus, despite the potential presence of a social selection effect and despite the kin and financial resources that could cushion the causative effects of a union dissolution, these are not sufficient to explain differences in GHQ-12 caseness among those who experienced one or more than one union dissolution and among those who recently experienced a partnership break-up compared with those who experienced a union dissolution a longer time ago. However, it should be noted that there is likely to be unmeasured heterogeneity in the propensity to separate, which may relate to psychological well-being. This could not be tested since there is no information on mental health prior to union dissolution in the dataset.

This study has a number of limitations. It has related wellbeing at the time of the survey to retrospective data on partnership histories to look over across the individual's partnership formation and dissolution history. The level of well-being before the union transition is not known. Prospective data are more suitable to examine the impact of union transitions on psychological well-being by comparing well-being before, during and after the transition. Another limitation is that this study did not examine the role of social networks. Psychological distress has been found to be positively associated with low levels of social support ${ }^{15}$ but there are no data on social support or networks in the first wave of UKHLS. Also, people who are living alone may benefit from the protective effects of being in a partnership with someone who is not living with them, but there is no 
question on Living-Apart-Together (LAT) relationships in UKHLS. Nevertheless, this study provides new insights into how partnership history matters in the psychological well-being of those who are living alone in mid-life.

\section{What is already known on this subject}

- Union dissolution is in several ways associated with psychological well-being: well-being deteriorates for a relatively short period around the dissolution and is adversely affected by the experience of multiple union dissolutions. Poor psychological well-being is related to poor physical health and higher mortality rates. However, it is not clear whether both the duration since the most recent union dissolution and the number of union dissolutions would be associated with psychological well-being when considered jointly in statistical models.

\section{What this study adds}

- General Health Questionnaire 12 caseness is positively associated with the number of union dissolutions and negatively with the duration since the most recent union dissolution among 50-64-year-old British men and women living alone. This association holds when including both partnership variables in the models and is not mediated by parenthood status, socioeconomic status or physical health. These findings suggest that psychological well-being is affected in both the short and long term by union dissolution.

Acknowledgements The United Kingdom Household Longitudinal Survey (UKHLS) is conducted by the Institute for Social and Economic Research (ISER) at the University of Essex. UKHLS data were accessed via the UK Data Archive. Neither the original data creators, depositors or funders bear responsibility for the further analysis or interpretation of the data presented in this study. The authors also gratefully acknowledge the comments and suggestions by two anonymous reviewers.

Contributors DD, AB, ME and JF discussed the conception and design of the study, and gave approval of the final version to be published. DD conducted the data analysis and has written the first draft. $A B, M E$ and JF revised the first draft and contributed towards the final version.

Funding This work was supported by the Economic and Social Research Council (ESRC) [grant number RES-625-28-0001] that funds the ESRC Centre for Population Change (CPC) where this study was carried out. CPC is a joint initiative between the Universities of Southampton, St. Andrews, Dundee, Edinburgh, Stirling and Strathclyde, in partnership with the Office for National Statistics (ONS) and the General Register Office Scotland (GROS) (now the National Records of Scotland, NRS). The findings, interpretations and conclusions expressed in this study are entirely those of the authors and should not be attributed in any manner to ONS or GROS/NRS.

Competing interests None.
Provenance and peer review Not commissioned; externally peer reviewed.

\section{REFERENCES}

1 Gardner J, Oswald AJ. Do divorcing couples become happier by breaking up? J Royal Stat Soc A 2006;169:319-36.

2 Marks NF. Flying Solo at Midlife: Gender, Marital Status, and Psychological Well-Being. J Marriage Fam 1996;58:917-32.

3 Pinquart M. Loneliness in married, widowed, divorced, and never-married older adults. J Soc Pers Relationships 2003;20:31-53.

4 Wade TJ, Pevalin DJ. Marital transitions and mental health. J Health Soc Behav 2004;45:155-70.

5 Blekesaune M. Partnership transitions and mental distress: investigating temporal order. J Marriage Fam 2008;70:879-90.

6 Peters A, Liefbroer AC. Beyond marital status: partner history and well-being in old Age. J Marriage Fam 1997;59:687-99.

7 Chandler J, Williams M, Maconachie M, et al. Living alone: its place in household formation and change. Sociol Res Online 2004;9:chandler.

8 Demey D, Berrington A, Evandrou M, et al. The changing demography of mid-life, from the 1980s to the 2000s. Popul Trends 2011;145:16-34

9 Glaser K, Murphy M, Grundy E. Limiting long-term illness and household structure among people aged 45 and over, Great Britain 1991. Age Soc 1997;17:3-19.

10 Hughes ME, Waite LJ. Health in household context: living arrangements and health in late middle age. J Health Soc Behav 2002:43:1-21.

11 Cho HJ, Lavretsky H, Olmstead R, et al. Prior depression history and deterioration of physical health in community-dwelling older adults - a Prospective Cohort Study. Am J Geriatr Psychiatry 2010;18:442-51.

12 von Ammon Cavanaugh S, Furlanetto LM, Creech SD, et al. Medical illness, past depression, and present depression: a predictive triad for in-hospital mortality. Am J Psychiatry 2001;158:43-8.

13 Larsson K, Silverstein M. The effects of marital and parental status on informal support and service utilization: a study of older Swedes living alone. J Aging Studies 2004;18:231-44

14 Hays JC. Living arrangements and health status in later life: a review of recent literature. Public Health Nurs 2002;19:136-51.

15 Stone J, Evandrou M, Falkingham J. The transition to living alone and psychological distress in later life. Age Ageing 2013;42:366-72.

16 Clavarino A, Hayatbakhsh MR, Williams GM, et al. Depression following marital problems: different impacts on mothers and their children? A 21-year prospective study. Soc Psychiatry Psychiatr Epidemiol 2011;46:833-41.

17 Gray M, De Vaus D, Qu L, et al. Divorce and the wellbeing of older Australians. Ageing Soc 2011;31:475-98.

18 Dykstra PA, Keizer R. The wellbeing of childless men and fathers in mid-life. Ageing Soc 2009:29:1227-42.

19 McFall SL. Understanding Society - The UK Household Longitudinal Study, Wave 1, 2009-2010, User Manual. Colchester: University of Essex, 2011.

20 Lynn P, Burton J, Kaminska O, et al. An initial look at non-response and attrition in Understanding Society. Understanding Society Working Paper Series 2012;2. https:// www.understandingsociety.ac.uk/research/publications/working-paper/understandingsociety/2012-02.pdf

21 Goldberg DP, Oldehinkel T, Ormel J. Why GHQ threshold varies from one place to another. Psychol Med 1998;28:915-21.

22 Demey $\mathrm{D}$, Berrington $\mathrm{A}$, Evandrou $\mathrm{M}$, et al. Pathways into living alone in mid-life: diversity and policy implications. Adv Life Course Res 2013;18:161-74.

23 Huijts T, Kraaykamp G, Subramanian SV. Childlessness and Psychological Well-Being in Context: A Multilevel Study on 24 European Countries. Eur Sociol Rev 2013:29:32-47.

24 Evenson RJ, Simon RW. Clarifying the relationship between parenthood and depression. J Health Soc Behav 2005;46:341-58.

25 Monden CWS, Uunk WJG. For better and for worse: the relationship between union dissolution and self-assessed health in European panel data. Eur J Popul 2013;29:103-25.

26 Diener $E$, Suh EM, Lucas RE, et al. Subjective well-being: three decades of progress. Psychol Bull 1999:125:276-302.

27 Diener E, Lucas RE, Scollon CN. Beyond the Hedonic Treadmill. Revising the Adaptation Theory of Well-Being. Am Psychol 2006;61:305-14. 